during the seven months in which this plan has been pursued we have had no more appearance of erysipelas.

Thus my wards, although by no means models, as regards their principle of construction or the space allowed between the beds, appear perfectly free from any liability to hospital diseases.

Edinburgh, July 22nd, 1870.

\section{ON THE \\ LOCAL AND SPONTANEOUS ORIGIN OF ENTERIC FEVER.*}

\section{Br CHARLES E. PRIOR, M.D.}

F IT is an utter impossibility that any science can advance whose fundamental axioms are a matter of uncertainty or of suspicion. No history can be appealed to with confidence, however elaborate it may appear, whose author lies under the suspicion of having refrained to consult the authorities whose views were unfavourable, or of having allowed his imagination in any minor matter to colour his representation of past occurrences. Little as they may affect the main beauties of the poet, the critical mind recurs again and again to the blots and scratches of the recently discovered folio of Shakspeare, and the authority of the entire emendations awaits confirmation until the doubts on the threshold are cleared up.

And so it is in medical researches, and very especially in those connected with that most important subject, the etiology of enteric fever. Led away by the declamation of this or that professor, gratified it may be by the deep research and protracted labours of another, it seems but a small return to accept their occasionally very crude conclusions as to the causation of the disease; by-and-by wil arise uneasy doubts; there will be frequent recurrence to the awkward crux so glibly disposed of ; and, unless we feel inclined to substitute intemperance and assertion for argument there is little left but to go over the entire ground again.

It is non-results such as these that have a painful effect on the standing of medicine as a science, and give too much point to the occasional jeers of the learned of other professions, who yet make insufficient allowance for the difficulties with which we have to contend. The naturalist as he passes along the highway hears the chirp of the linnet over-head; and if he be a true observer, or even a truthful disciple of other observers, a whole history lies before him in that one note-the flight, the plumage, the habits of the bird-nay, the very nature of the country. A plant is brought to the botanist in his study; he inquires the locality where it was found, examines its growth and strength, and a series of stable conclusions as to the soil, the climate, and the natural productions with which it may probably be found associated are at once before his mental vision. From step to step and conclusion to conclusion the astronomer and the geologist advance with assurance along the track of their absorbing pursuits. Circumstances have denied to the science of medicine conclusions so secure and progress so encouraging; but I think I do not err in saying that there is a something wanting in our method of research which may account for our comparatively meagre progress, our occasional and most mortifying drawbacks in the path of discovery. Were medical research more systematised; were certain problems submitted as a matter of business to experts, and their research rigorously confined thereto; were their resuits public property rigidly watched by vigilant commissions, and not mere desultory observations ex panded into axioms for the sake of premature celebrity, and adhered to with the obstinacy of personal interest, - I conceire that medical seience would be now in a far more advanced stage than it is.

Such a problem is the local and spontaneous generation of enteric fever-denied by many, doubted by most, as sented to by others from sheer ennui, vigorously and enthusiastically asserted by some, accepted by a great portion of the public as an ixiom and fundamental (as Cromwell would term it) of sanitary levislation.

\footnotetext{
* Head, Oet, $1 \times 68_{2}$ befure the S. Midland Branch of the B.MI, \pm ssoc,
}

Do we clearly understand the importance of what is conveyed by an assent to the doctrine of spontaneous generation?

In the infancy of science, Aristotle considered that insects, fishes, and mollusca were capable of spontaneous generation. Plutarch, we are informed, made an exception in favour of mice. We may smile at these absurdities, and congratulate ourselves on the progress of modern science but it is only within the last quarter of a century that the wonderful stages of existence of most of the entozoa have been recognised in England, and the term " equivocal generation" may be found in works of authority by living authors. With the advance of investigation $I$ am disposed to think that " equivocal generation" will recede, like the spontaneous generation of Aristotle, with those members of the animal creation of whose generation we know nothing, and whom our present methods of observation are insufficient to track. The more that improved methods of observation are brought to bear upon it, the more does spontaneous generation recede. We can already enumerate thousands of existences, both animal and vegetable, to which this origin was once assigned, whose generation has now been traced and established. Some still remain an enigma; but, judging of the future by the past, or of the unknown by the known, it is fair to say that the burthen of proof of spontaneous generation rests with its advocates. Lamarck conceived that the monad, the then lowest known form of animal life, might be produced by spontaneous generation; but Ehrenberg admits nothing of the sort. The speculations of Pling or Aristotle, at which we now smile, are but a counterpart of the belief of the ignorant of our own days (and ignorance does not walk in hobnailed shoes alone, nor is it excluded from the halls of the wealthy or the heads that wear coronets). We are all prone to judge by appearances. I went last year to a copper mine. My guide, an intelligent foreman, was very anxious that I should see the most remarkable process of all-" iron made into copper." I assured him that this was an impossibility that the transmutation of metals had been abandoned 200 years ago; but that, perhaps, when I saw it, I might explain what gave the appearance of its doing so. He took me to the place. "There it is, Sir; you see the iron goes and the copper comes." And certainly the ingenious chemical process employed gave everg colour to his statement I explained the matter to him as well as I could: I knew whence came the copper, and what became of the iron; but I cannot with the same ease explain whence comes the minute spore that breeds the mildew in cheese, which tranquil ignorance assumes to be generated by damp. The idle and unthinking may assume that the lichen on the wall is generated by the damp of the cellar, the mildew of wheat by the atmosphere, or the mites of cheese by decomposition; the scientific student only sees in any case of so-called equivocal generation the necessity for further research.

It has been attempted to bring the question of spontaneous generation to the test of actual experiment. Some quarter of a century ago the reading public of England was fascinated by the appearance of a work ("The Vestiges of Creation") in which the transcendentalism of Oken, Goethe, and Geoffroy St. Hilaire was first introluced to a general audience (though not its first introduction to the scientific world). From experiments therein recorded it would appear that, under certain conditions, acari of peculiar form had made their appearance in certain solutions without the presence of oroanic germs; but experiments of a similar character have been subsequently made by Schwann, and this with a negative result; and the edifice has been crowned, so to speak, by MI. Pasteur, who bas shown that the infusions employed were capable, if supplied with organic germs, of producing living infusoria in profusion. In fact, spontaneous generation, under these rigorous tests, fades away to nothing. For ages it has been but a name to disguise our ignorance; and now the question has arrived at that point that it must either be clearly demonstrated (an impossibility !) or finally abandoned.

But it may be said, What has the spontaneous generation of infusoria, of plants, or animals to do with the spontaneous generation of disease, the more especially as we know that many diseases are spontaneously generated? To this I would reply, Mruch, very much. In the first place, we thereby clear the field of a whole croup ci parasitical diseases. Instead of searching about for the climatic 
causes of trenia or guinea-worm, we are disposed to feel astonished that our forefathers should have overlooked their immense powers of propagation. We have seen favus or achorion Schonleinii grown on slices of apple, or the fearful foot-fungus of India reproduced by cultivation from the germ by Mr. Berkeley; we have read the discoveries of Fon Siebold; and as regards parasitical diseases our ideas of their generation are fixed and settled.

Nor is this all. We have recognised in the entire group of exanthemata certain peculiar characteristics which admit, at least, the possibility of their being a low form of fungoid nature. The proposition is a startling one; but the rapid growth of the characteristic eruption when once the germ has been received, and the immunity from second attacks, appear to point to a pabulum in the system exhausted by the first crop. I cannot enter further into this branch of the argument. I merely notice it en passant. The theory, I believe, has been treated at length by an American physician, Dr. Salisbury. We scout with the utmost derision the idea of a spontaneous origin of the too familiar enthetic diseases; so much so that if any professional brother is sufficiently weak to admit an accidental syphilitic inoculation (an occurrence by no means impossible), our estimate of his sagacity immediately sinks; and yet, if the following argument be valid, it is surely at least as applicable to enthetic disease as to any other. It is this: "The origin of all these diseases is unknown to us. They must have had a beginning-a first case. Why, then, may not first cases crop up now and then amongst and around us ?"

This argument, pointed and sharpened by that magnificent disregard for the research and opinions of others which charucterises French travellers and English authoresses, has found its way into Miss Nightingale's " Notes on Nursing." The passage is altogether so remarkable, and has exercised so remarkable an effect, that I venture to transcribe ii entire.

"Is it not living," says this lady, "in a continual mistake to look upon aiseases as we do now-as separate entities which must exist, like cats and dogs? instead of looking upon them as conditions, like a dirty and a clean condition, and quite as much under our control; or rather as the actions of kindly nature against the conditions in which we have placed ourselves.

"I was brought up, both by scientific men and ignorant women, distinctly to believe that small-pox, for instance, was a thing of which there was once a first specimen in the world, which went on propagating itself in a perpetual chain of descent, just as much as there was a first dog (or a first pair of dogs); and that small-pox would not begin itself any more than a new dog would begin without there having been a parent dog.

"Since then I have seen with my eyes, and smelt with my nose, small-pox growing up in first specimens, either in close rooms or in overcrowded wards, where it could not by any possibility have been ' caught', but must have begun. Nay, more; I have seen diseases begin, grow up, and pass into one another. Now dogs do not pass into cats. I have seen, for instance, with a little overcrowding, continued fever grow up; and with a little more, typhoid fever; and with a little more, typhus; and all in the same ward or hut.

"Would it not be far better, truer, and more practical, if we looked upon disease in this light? For diseases, as all experience shows, are adjectives, and not substantives." *

We may fairly hold our breath at the startling prodigality of assertion in this remarkable passage. Diseases adjectives! I fear too many of us have a distinct personal experience of their substantive nature. Continued fever from a little overcrowding, a little more typhoid, a little more typhus! What will Dr. Murchison say to such general pathology as this? Small-pox springing up in first specimens teste the infallible eyes, teste, moreover, the infallible nose! And yet this passage has taken no trivial hold of the public mind, and has been currently appealed to whenever the origin of exanthematous disease from "dirt"whatever that may mean - or from "overcrowding" wherever that may be supposed to begin-has been called in question. Many a tyro has been visited with a triumphant knock-down from Miss Nightingale when enunciating the old-fashioned doctrine of infection, and remitted to another six months' course of whitewash, ventilation, painted walls, and patent waterclosets. If occasionally we

\footnotetext{
* Notes on Nursing, p. 10.
}

ourselves have felt a little humiliation when our science has been set at nought, our conclusions doubted, I cannot say that the circumstance is altogether to be regretted, should it induce us once for all to abandon our vacillating theories, to throw in our little observations honestly and faithfully for the general benefit, and to seek the reward of our labours in establishing science on a firm basis, not in an evanescent and fruitless popularity.

To such speculations as those of Miss Nightingale and her adherents the answer is not far to seek. Never, I will venture to say, since small-pox was first introduced into Europe has a sporadic case occurred. To trace the germ with eyes or nose, as this good lady would appear to think possible, would be a task like that of tracing the gnats of summer to their home, or the spore of the sea-fern to its native land. Small-pox has come to the prisoner in solitary confinement and to the prince upon the throne. A letter has carried it, the wind has wafted it in directions that have baffled the investigation of man; but there are limits which it cannot overpass. From the beginning of the world the North American Indians had remained exempt from this disease (and the circumstance appears to me one argument against Cuvier's theory of their Mongolian origin) till one fatal day, a few years after the discovery of Hispaniola, a negro covered with pustules was landed on the American shore, and from him the disease spread over the entire continent before it could be grappled with. No history can convey the desolation it has effected. Mighty nations have dwindled before it to feeble tribes; whole tribes have ceased to exist.

To this day the Maories of New Zealand are exempt from the disease, though, as far as local causes go, perhaps they are as frequent and as disgusting amongst them as with most savages. Let it once be introduced there, and probably the experience of America will recur. But the physician who is called to a case of small-pox knows that in the great majority of cases it will be useless to attempt to trace the infection; he recognises the fact, and addresses himself to practical matters; and if this be true of the most marked and typical of the exanthemata, it will be additionally true of others whose infection is more feeble, and whose characteristics are less distinct.

(T'o be concluded.)

CASE OF

\section{SLOUGHING PHAGED ENA OF THROAT,} H EMORRHAGE, AND LIGATURE OF COMMON CAROTID.

\author{
UNDER THF CARE OF
}

R O B R T G R A A M E, Esq., STAFF-SURG. R.N., GRBENWICH HOSPITAL.

(Reported by Assist.-Surg. P. KEELAN, R.N., and communicated by the DiRector.Gentral of THE MedicaI. DEPARTMENT OF THE NAYY.)

Jонм F-, aged forty-three, an out-pensioner, was admitted into Greenwich Hospital on the 12th of April, 1869, suffering from advanced phthisis, accompanied by occasional hæmoptysis. A month after his admission ulceration of the back of the pharynx commenced, and, in spite of all topical and constitutional treatment, speedily extended on either side, implicating both tonsils, and eroding the whole of the uvula and greater part of the soft palate. For some time the process of ulceration appeared to have come to a standstill, but on the 16th of October last a large ragged slough was found situated behind the right anterior pillar of the fauces, and extending down into the pharynx. The sloughing action progressed, and slight hæmorrhage by the nose and mouth first appeared on the 4th of December. This recurred more profusely on the next day (5th) ; and, as the blood appeared to be derived from the posterior nares, these were plugged. The bleeding ceased for the time; but on December 7 th, half an hour after midnight, during a fit of coughing, profuse arterial hæmorrhage suddenly took place, coming from the right side of the throat, and also trickling from the right ear, in which hearing had been for some time lost. Pressure 